\title{
Cost-comparison analysis of FIB-4, ELF and fibroscan in community pathways for non- alcoholic fatty liver disease
}

\author{
Ankur Srivastava ${ }^{1 *} \mathbb{D}$, Simcha Jong ${ }^{2}$, Anna Gola ${ }^{3}$, Ruth Gailer ${ }^{4}$, Sarah Morgan ${ }^{5}$, Karen Sennett ${ }^{6}$, Sudeep Tanwar ${ }^{1}$,
} Elena Pizzo ${ }^{7}$, James O'Beirne ${ }^{1}$, Emmanuel Tsochatzis ${ }^{1}$, Julie Parkes ${ }^{8}$ and William Rosenberg ${ }^{1}$

\begin{abstract}
Background: The identification of patients with advanced liver fibrosis secondary to non-alcoholic fatty liver disease (NAFLD) remains challenging. Using non-invasive liver fibrosis tests (NILT) in primary care may permit earlier detection of patients with clinically significant disease for specialist review, and reduce unnecessary referral of patients with mild disease. We constructed an analytical model to assess the clinical and cost differentials of such strategies.

Methods: A probabilistic decisional model simulated a cohort of 1000 NAFLD patients over 1 year from a healthcare payer perspective. Simulations compared standard care (SC) (scenario 1) to: Scenario 2: FIB-4 for all patients followed by Enhanced Liver Fibrosis (ELF) test for patients with indeterminate FIB-4 results; Scenario 3: FIB-4 followed by fibroscan for indeterminate FIB-4; Scenario 4: ELF alone; and Scenario 5: fibroscan alone. Model estimates were derived from the published literature. The primary outcome was cost per case of advanced fibrosis detected.

Results: Introduction of NILT increased detection of advanced fibrosis over 1 year by 114, 118, 129 and 137\% compared to SC in scenarios 2, 3, 4 and 5 respectively with reduction in unnecessary referrals by $85,78,71$ and $42 \%$ respectively.

The cost per case of advanced fibrosis (METAVIR $\geq F 3$ ) detected was $£ 25,543, £ 8932, £ 9083, £ 9487$ and $£ 10,351$ in scenarios 1, 2, 3, 4 and 5 respectively. Total budget spend was reduced by 25.2, 22.7, 15.1 and 4.0\% in Scenarios 2, 3,4 and 5 compared to $£ 670 \mathrm{~K}$ at baseline.

Conclusion: Our analyses suggest that the use of NILT in primary care can increases early detection of advanced liver fibrosis and reduce unnecessary referral of patients with mild disease and is cost efficient. Adopting a two-tier approach improves resource utilization.
\end{abstract}

Keywords: Enhanced Liver fibrosis (ELF), Fibroscan, |NAFLD, Cirrhosis detection, Cost savings

\section{Background}

The health, societal and economic burden of chronic liver disease (CLD) is substantial and represents a public health priority $[1,2]$. CLD is the 5th commonest cause of death in the United Kingdom, and the only one in the top five that is increasing [3]. With rising prevalence of risk factors for liver disease including obesity and alcohol, pressure on

\footnotetext{
*Correspondence: Ankur.srivastava@nhs.net

${ }^{1} \mathrm{UCL}$ Institute for Liver and Digestive Health, Royal Free Campus, London NW3 2PF, UK

Full list of author information is available at the end of the article
}

healthcare resources is likely to intensify. Better and earlier detection of CLD in primary care is key to improving health outcomes and associated costs [4].

Non alcoholic fatty liver disease (NAFLD) is the commonest cause of deranged liver function tests (LFTs) in primary care [5]. Only a minority (5\%) of these cases progresses to clinically significant liver disease [6] whilst evidence highlights fibrosis severity as the key determinant of liver related morbidity and mortality $[7,8]$. The identification of patients with significant liver disease is a primary care challenge, where accurate fibrosis assessment is

(c) The Author(s). 2019 Open Access This article is distributed under the terms of the Creative Commons Attribution 4.0 International License (http://creativecommons.org/licenses/by/4.0/), which permits unrestricted use, distribution, and reproduction in any medium, provided you give appropriate credit to the original author(s) and the source, provide a link to the Creative Commons license, and indicate if changes were made. The Creative Commons Public Domain Dedication waiver (http://creativecommons.org/publicdomain/zero/1.0/) applies to the data made available in this article, unless otherwise stated. 
limited by a reliance on LFTs, which are poor discriminators of liver fibrosis [9].

In the current 'standard care' (SC), primary care physicians (PCP) assess the severity of a patient's liver disease and subsequent need for specialist referral based on history, examination, blood tests including LFTs and ultrasound.

Patients referred to secondary care deemed to have significant liver disease due to NAFLD may benefit from active management (including consideration for clinical trials of emerging therapies for NAFLD and fibrosis) [2, 10]. Patients with cirrhosis will be enrolled in pathways of care that improve outcomes through targeted screening and treatment for complications of cirrhosis including portal hypertension [11] and hepatocellular carcinoma (HCC) [12]. However, current primary care approaches result in the referral of many patients that do not have significant liver fibrosis, placing a burden on secondary care services, incurring unwarranted costs and generating unnecessary inconvenience and anxiety for patients [13]. Furthermore a significant number of patients with advanced liver fibrosis are missed and not referred to secondary care. These patients have been falsely reassured and will silently progress before presenting with end-stage liver disease or liver cancer.

The use of non-invasive liver fibrosis tests (NILT) [14] may improve PCP staging of disease $[4,15]$ and referral practice but there is a lack of health-economic evidence about the use of NILT in fatty liver disease to inform clinicians, commissioners and policy makers about the value of such strategies. In this study, we developed a probabilistic decision analytical model to investigate the clinical and cost impact of primary care risk stratification of patients with NAFLD.

\section{Methods}

A liver working group, comprising primary care physicians and secondary care liver specialists, commissioners, public health practitioners and patient representatives was formed in the London Boroughs of Camden and Islington to develop new pathways of care for patients with NAFLD. Part of the strategy was to establish current practice (standard care (SC)) (Fig. 1) and to establish pragmatic guidance on how to improve the identification of NAFLD cases with advanced liver disease for referral to secondary care. In the first instance, PCP favoured the selection of patients with deranged liver function tests (LFT) even though it was agreed that this would miss a minority of cases with liver fibrosis who have normal LFTs.

\section{Probabilistic decision model}

A probabilistic decision analytical simulation model was created using Microsoft Excel Software (version16.23, 2019). The model piloted competing primary care risk stratification diagnostic strategies for 1000 patients with a confirmed diagnosis of NAFLD (Fig. 2). The average patient was 50 years old with elevated transaminases. The cycle length was 1 year.

\section{Competing Strategies in the Model and Analyses}

We modelled the standard care in the UK National Health Service (NHS) (scenario 1). The use of FIB-4 and ELF in a two-tier stratification approach (scenario 2) was modelled to replicate a local pilot pathway - the Camden and Islington NAFLD pathway [13]. Following an independent evaluation of NILT public health consultants favoured the use of FIB-4 over the NAFLD Fibrosis Score, in part due to a lack of standardization in the diagnosis of diabetes. Fibroscan is increasingly established in secondary care practice, and was incorporated to assess its performance in place of ELF in a two-tier strategy (Scenario 3). One-tier approaches were also considered in which SC was supported by ELF (scenario 4), or fibroscan alone (Scenario 5).

In all scenarios SC delivered by PCPs included history, physical assessment followed by investigation of liver function, tests for viral, immune and metabolic causes of liver disease and an ultrasound scan in order to make an assessment of the risk of advanced liver fibrosis. This was classified as a binary outcome with the case deemed to be at 'high risk' of advanced liver disease necessitating referral to a specialist, or at 'low risk' and thus appropriate for management in primary care. This decision process required 3 PCP consultations, 3 routine bloods tests and 1 ultrasound scan. In scenarios 2 and 3, SC was supported by the calculation of a FIB- 4 score in all patients to improve the identification of patients at risk of advanced fibrosis (METAVIR $\geq$ F3). Low risk patients (FIB-4<1.30) were managed in primary care whilst high-risk patients (FIB-4 > 3.25) were referred to a specialist in secondary care. Patients with indeterminate scores (FIB-4 1.30-3.25) required an ELF test (Scenario 2) or a community fibroscan (Scenario 3). Published cut-offs were used to identify cases at increased risk of advanced fibrosis $(\geq 10.3$ for ELF and $\geq 7.9 \mathrm{kPa}$ for Fibroscan). A fibroscan failure rate of $5 \%$ was assumed [47]. For patients managed in Scenario 4, SC was followed by ELF test for all patients and in Scenario 5 $\mathrm{SC}$ was followed by fibroscan for all patients.

Patients identified as being at high-risk of advanced fibrosis were referred to a secondary care specialist. Evaluation included further blood tests, fibroscan, imaging including US scan (50\% of cases, informed by local audit), CT scan ( $5 \%$ of cases, informed by local audit), MRI Liver (5\%, informed by local audit) and liver biopsy (15\% of cases, informed by local audit). Patients deemed to not have advanced fibrosis (false positive) would be discharged to primary care, whilst those confirmed with advanced fibrosis would enter recognised surveillance pathways. 


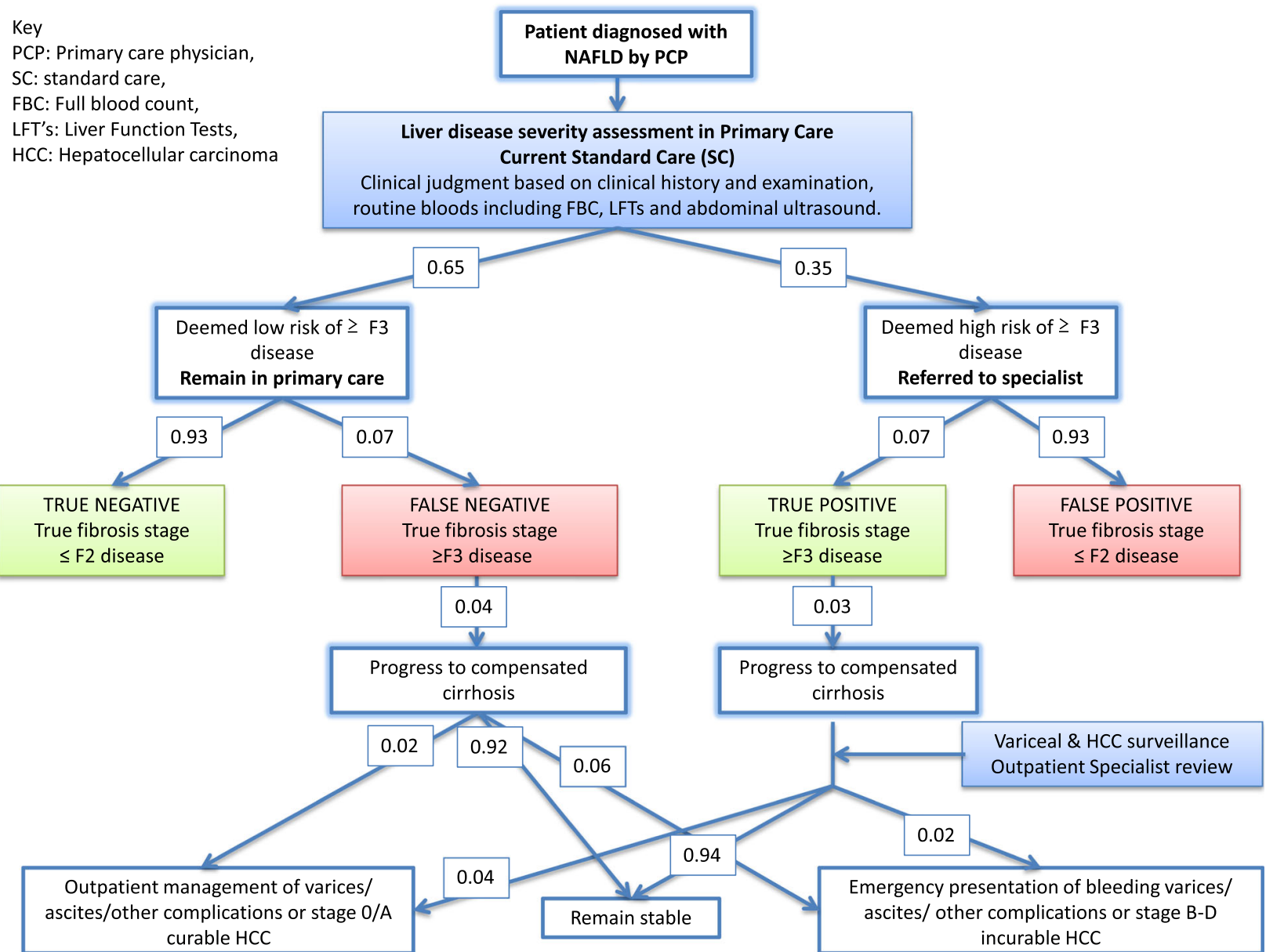

Fig. 1 Schematic simulating current 'standard of care' patient journey. Simplified simulated journey of a patient with NAFLD through the healthcare system after primary care assessment using standard of care over a 1-year timeframe (see Table 1 and Table 2 for references). The diagnostic performance of the primary care assessment has four outcomes - 1) 'True positive'; Patients deemed to be at high risk for advanced fibrosis subsequently confirmed as having $\geq F 3$ fibrosis after specialist assessment. Patients will be actively managed in secondary care (including consideration for clinical trials). Patients with cirrhosis will be enrolled in pathways of care that improve outcomes through targeted screening and treatment for portal hypertension and hepatocellular carcinoma (HCC). 2) 'True negative'; Patients deemed to be at low risk for advanced fibrosis found to have SF2 disease. These patients are unlikely to suffer morbidity from their liver disease. Management in primary care should be focussed on managing reversible metabolic disorders. 3) 'False positive'; Patients deemed to be at high risk for advanced fibrosis in primary care but found to have $\leq F 2$ fibrosis. The pathway can be considered to have failed this group of patients, whom can be managed effectively in primary care with weight loss and exercise. 4) 'False negative'; Patients deemed to be at low risk for advanced fibrosis who have $\geq$ F3 fibrosis. This cohort of patients have been falsely reassured and represent a failure of the pathway as they remain in primary care unless they present with complications of CLD if their disease progresses, at which point interventions are increasingly limited

The time horizon for the base-case was 1 year to assess short-term benefits, likely to relate to resource utilisation. A 5- year timeframe was applied to assess the longer-term implications.

\section{Clinical data inputs}

A comprehensive literature search informed model parameters. The data were critically assessed to ensure suitability for this study and were supplemented by expert opinion when required.
The model assumed an intention-to-diagnose strategy. All patients would be managed according to the pathways. SC performance is poorly documented, but estimates were extrapolated from available studies $[13,16$, 17]. Advanced fibrosis ( $\geq \mathrm{F} 3$ fibrosis) prevalence was set at 7.5\% [5] and published sensitivities and specificities of FIB-4 [18, 19], ELF [19, 20] and fibroscan [19, 21] were used to predict stratification rates for low- and high- risk of advanced fibrosis (Table 1 and Fig. 3). Estimates of NAFLD disease progression were used to inform pathway performance (Table 2). 


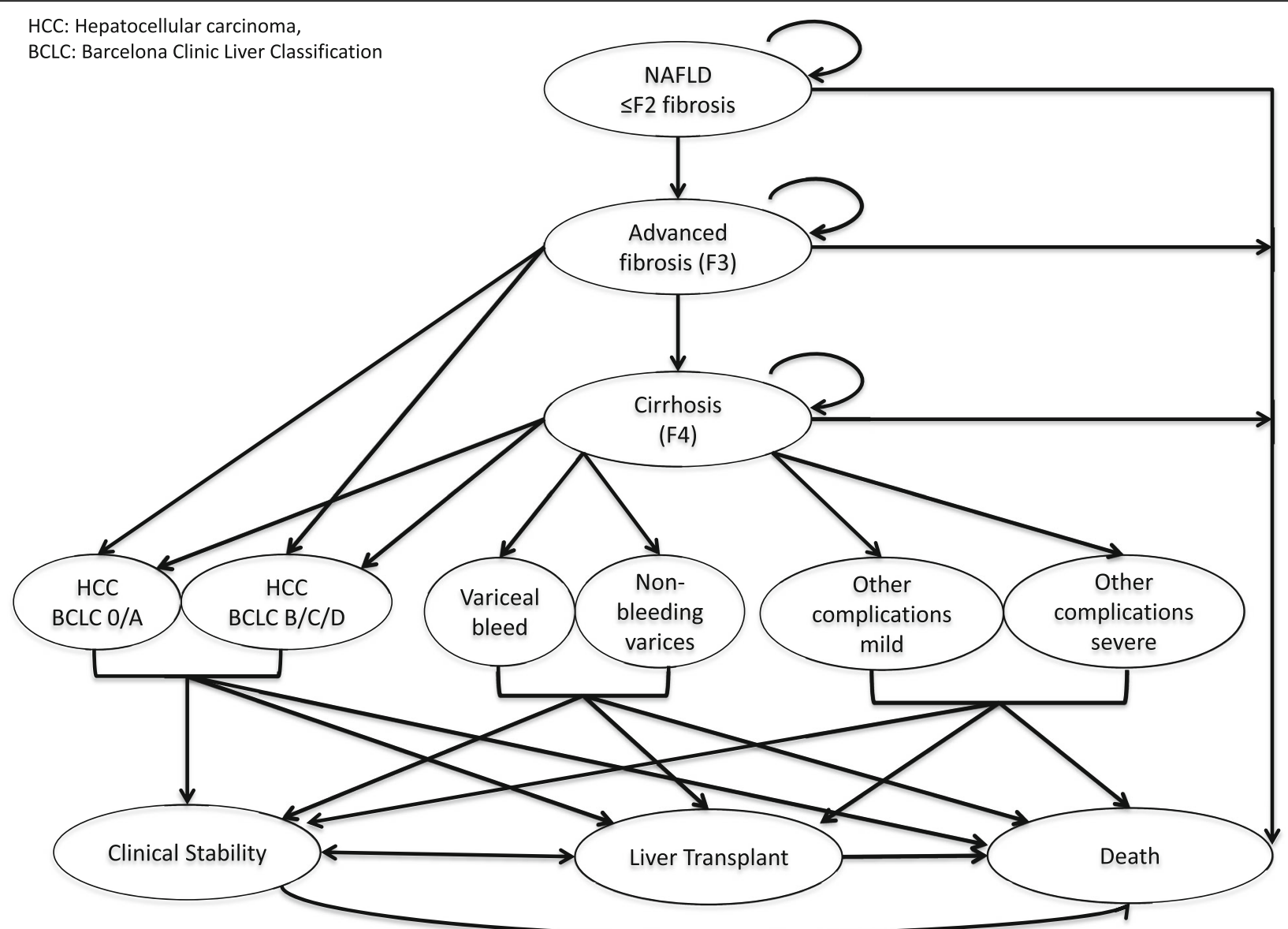

Fig. 2 Decision tree presenting overview of transition of a patient with NAFLD through the model. In the model, a patient with NAFLD and $\leq F 2$ fibrosis could remain well, progress to F3 fibrosis or die. A patient with F3 fibrosis could remain well, progress to compensated cirrhosis, develop HCC or die. Patients with compensated cirrhosis could remain stable, develop a complication of cirrhosis, undergo liver transplantation or die. The model differentiated early stage complications (non-bleeding varices detected by surveillance endoscopy, Barcelona Clinic Liver Cancer (BCLC) stage 0/A HCC and mild/moderate 'other' complication including ascites, jaundice and hepatic encephalopathy managed as outpatient), from late stage complications (bleeding varices, BCLC stage B-D HCC and severe 'other' CLD complications necessitating inpatient admission)

\section{Cost data inputs}

A healthcare payer perspective was adopted. Costs were derived from published resources and local costing tariffs (February 2015) (Table 3) for the UK. A 3.5\% discount rate was applied. Direct healthcare costs included PCP consultations, blood tests and ultrasound scans. The cost of FIB-4 was considered to be $£ 0$, as ALT, AST and platelet tests were incorporated as 'routine blood tests'. ELF was priced at $£ 42$, the quoted rate charged to the Camden and Islington CCG in their pathway, and fibroscan was priced at $£ 43$ [19]. In secondary care, the costs incurred related to specialist consultations, investigations including liver biopsy

Table 1 Test performance and Disease prevalence estimates

\begin{tabular}{|c|c|c|c|}
\hline Test characteristics & Sensitivity & Specificity & Reference \\
\hline Standard of care & 0.35 & 0.65 & Expert Opinion $[16,17$ \\
\hline FIB-4 (cut off 1.30) & 0.84 & 0.74 & {$[18,19]$} \\
\hline FIB-4 (cut off 3.25) & 0.38 & 0.97 & {$[18,19]$} \\
\hline ELF & 0.80 & 0.90 & {$[19,20]$} \\
\hline Fibroscan & 0.82 & 0.84 & {$[19,21]$} \\
\hline Population and disease characteristics & \multicolumn{3}{|c|}{ Transition probability } \\
\hline Prevalence of advanced fibrosis in the general population & 0.075 & & [5] \\
\hline
\end{tabular}



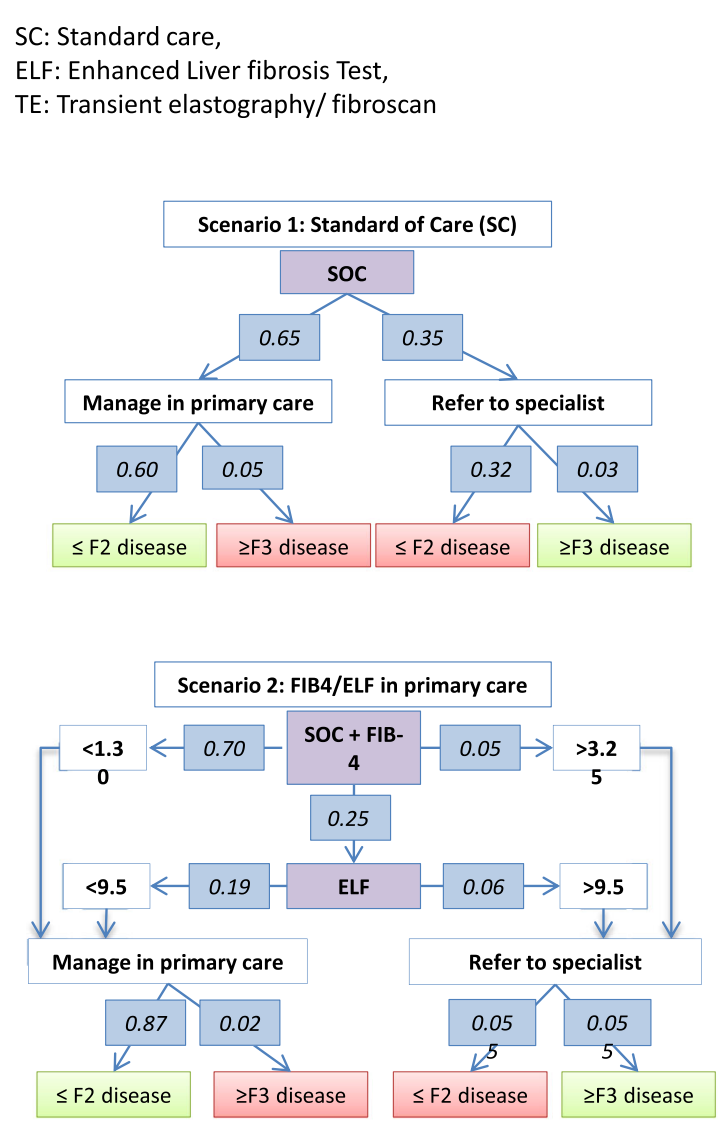

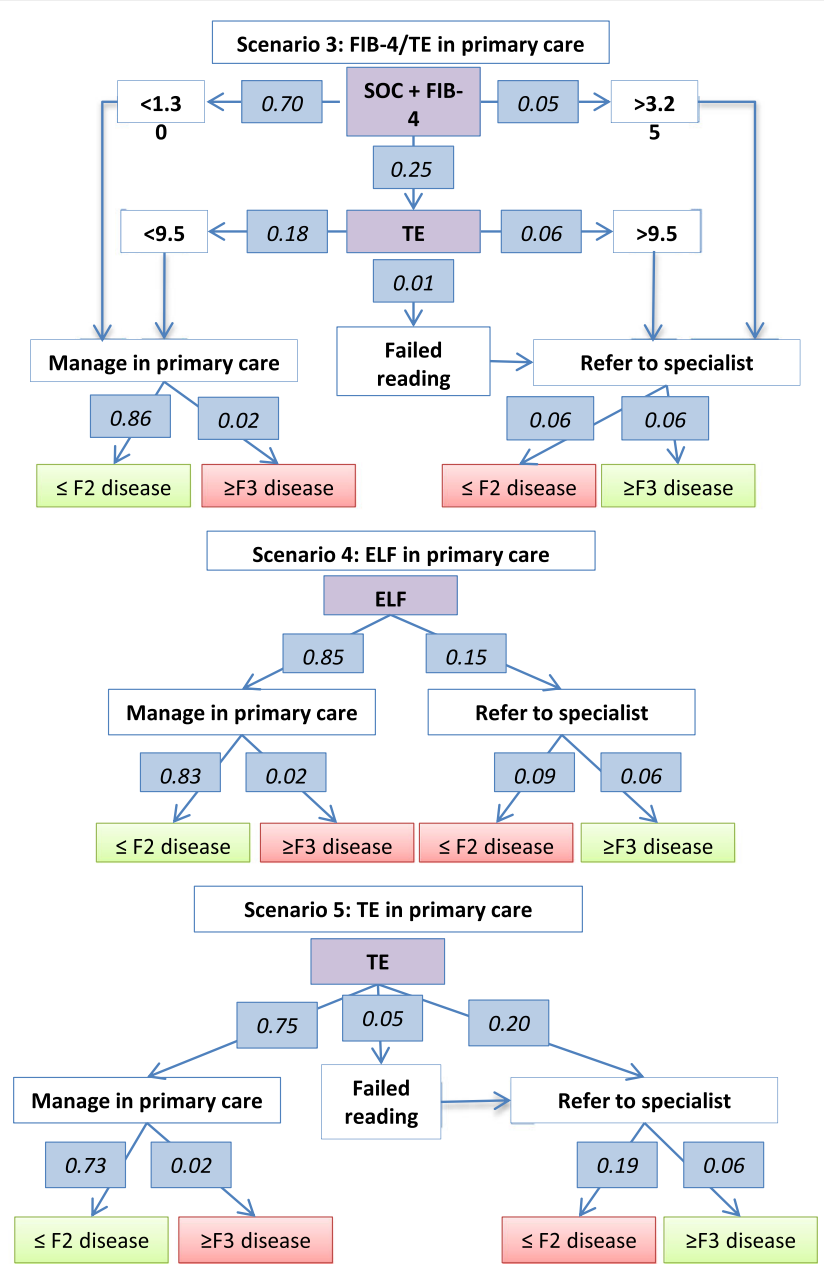

Fig. 3 Flow diagram depicting patient flow in each simulated scenario. Published test performances allowed prediction of true and false positive and negative rates for detection of advanced fibrosis $(\geq F 3)$ in each scenario

and expenditure related to HCC surveillance (6 monthly AFP and ultrasound) and variceal surveillance (2-3 yearly endoscopy). Finally, costs for the management of complications of CLD, including inpatient and outpatient costs, pharmacological treatment and surgical procedures including liver resection and transplant were obtained from the Royal Free London NHS Foundation Trust finance department.

The primary outcome measure was cost per case of advanced fibrosis detected - a surrogate for cost utility.

Secondary outcomes included unnecessary referral rates of patients with non-advanced disease, the severity of CLD complications, liver transplantation and mortality rates.

\section{Results}

\section{Clinical outcome}

The base case analysis for 1000 patients with NAFLD over a 1-year timeframe demonstrated 650 patients (65\%) were identified as being at low risk of advanced fibrosis and remained in primary care (scenario 1, SC). Of this group, 49 patients (8\%) had advanced fibrosis but remained in primary care inappropriately (false negative rate). The remaining 350 patients (35\%) were referred to a specialist. After specialist investigation, 93\% (324 patients) were determined to be at low risk (false positive rate) and discharged whilst 26 patients (7\%) were confirmed to have advanced fibrosis (true positive) and progressed on specialist pathways.

The impact of introducing non-invasive tests into primary care using FIB-4 and ELF (Scenario 2), FIB-4 and TE (Scenario 3), ELF alone (scenario 4) or TE alone (Scenario 5) was assessed (Fig. 4 and Table 4). Over the 1 year time-horizon, compared to SC these strategies reduced the relative referral rate from primary care to hospital by 70, 67, 56 and $43 \%$ for scenarios $2,3,4$ and 5 respectively; corresponding to 245, 223, 198 and 150 fewer referrals over 1 year per 1000 patients. This reduced the need for investigation performed in secondary care. The number of patients requiring imaging in secondary care reduced by 147, 134, 118 and 60 in 
Table 2 Transitional probability estimates used to populate the probabilistic analytical model for the base case (annual progression rates)

\begin{tabular}{|c|c|c|}
\hline Parameter/ Health state & Transition probability & References \\
\hline \multicolumn{3}{|l|}{ Population and disease characteristics } \\
\hline Prevalence of advanced fibrosis in the general population & 0.075 & [5] \\
\hline Reduction in fibrosis progression after GP management & 0.01 & [22], Author assumption \\
\hline Reduction in fibrosis progression after specialist review & 0.025 & [22] \\
\hline \multicolumn{3}{|l|}{ Mild/ No fibrosis (F0, F1, F2) } \\
\hline Remain healthy & 0.99 & [23-26] \\
\hline Develop F3 disease & 0.001 & {$[23,24]$} \\
\hline Mortality (all cause) & 0.005 & {$[25,27,28]$} \\
\hline Discharge from specialist services & 0.7 & Unpublished audit \\
\hline \multicolumn{3}{|l|}{ Advanced fibrosis (F3) } \\
\hline Remain healthy & 0.95 & {$[25,29,30]$} \\
\hline Develop F4 disease/ cirrhosis & 0.04 & {$[25,29,30]$} \\
\hline Develop HCC (without cirrhosis) & 0.004 & [29] \\
\hline Mortality (all cause) & 0.005 & [29] \\
\hline \multicolumn{3}{|l|}{ Compensated cirrhosis (F4) } \\
\hline Remain compensated & 0.93 & Calculated from other variables \\
\hline Develop varices & 0.03 & [31] \\
\hline Develop HCC & 0.003 & {$[32,34-37]$} \\
\hline Develop other complications (inc. jaundice, ascites, HE) & 0.02 & {$[29,31,32]$} \\
\hline Mortality (all cause) & 0.02 & {$[31,38,39]$, expert opinion } \\
\hline \multicolumn{3}{|l|}{ BCLC Stage 0 and A HCC } \\
\hline Cure (liver transplant) & 0.36 & [40] \\
\hline Cure (non transplant) & 0.39 & [40] \\
\hline Mortality (all cause) & 0.25 & [40] \\
\hline \multicolumn{3}{|l|}{$\mathrm{BCLC}$ stage $\mathrm{B}-\mathrm{D} \mathrm{HCC}$} \\
\hline Clinical stability (post TACE, RFA etc) & 0.24 & [41] \\
\hline Mortality (all cause) & 0.76 & [35] \\
\hline \multicolumn{3}{|l|}{ Varices detection in surveillance programme } \\
\hline Clinical stability & 0.92 & [42] \\
\hline Liver transplant & 0.01 & Expert opinion \\
\hline Mortality (all cause) & 0.07 & [33] \\
\hline \multicolumn{3}{|l|}{ Detection of varices after emergency presentation } \\
\hline Clinical stability & 0.73 & [43] \\
\hline Liver transplant & 0.02 & [42] \\
\hline Mortality (all cause) & 0.25 & [44] \\
\hline \multicolumn{3}{|l|}{ Mild/ Moderate 'other' complication } \\
\hline Clinical stability & 0.74 & [17] \\
\hline Liver transplant & 0.10 & [42] \\
\hline Mortality (all cause) & 0.16 & [17] \\
\hline \multicolumn{3}{|l|}{ Severe 'other' complication } \\
\hline Clinical stability & 0.45 & [17] \\
\hline Liver transplant & 0.10 & [42] \\
\hline Mortality (all cause) & 0.45 & [17] \\
\hline
\end{tabular}


Table 2 Transitional probability estimates used to populate the probabilistic analytical model for the base case (annual progression rates) (Continued)

\begin{tabular}{|c|c|c|c|}
\hline Parameter/ Health state & Transition probability & & References \\
\hline Severity of CLD Complication & No screening & Screening & \\
\hline Probability of $\mathrm{BCLC}$ stage $0+\mathrm{A} \mathrm{HCC}$ & 0.299 & 0.709 & [45] \\
\hline Probability of BCLC stage B - D HCC & 0.701 & 0.291 & [45] \\
\hline Detecting varices in surveillance programme & 0.0 & 0.60 & [42] \\
\hline Detecting varices after emergency presentation & 100.0 & 0.40 & [42] \\
\hline Mild/ moderate CLD 'other' complication & 0.527 & 0.622 & {$[17,46]$} \\
\hline Severe CLD 'other' complication & 0.473 & 0.378 & {$[17,46]$} \\
\hline
\end{tabular}

scenarios $2,3,4$, and 5 respectively, whilst $25,22,20$ and 10 fewer patients required endoscopy after 1 year per 1000 patients referred. The requirement for liver biopsy was reduced by 37, 33, 30 and 15 patients in scenarios 2 , 3,4 and 5 respectively. This translated into cost savings in secondary care investigation in the first year per 1000 patients referred of $£ 165,530.04, £ 150,184.67, £ 133,505.60$ and $£ 68,256.85$ for scenarios $2,3,4$ and 5 respectively.

These approaches resulted in reductions in referral of patients with non-advanced liver fibrosis (deemed "unnecessary" referrals) by $85,78,71$ and $42 \%$ (absolute reduction) in scenarios $2,3,4$, and 5 respectively compared to scenario 1; corresponding to $275,253,231$ and 137 reduction in inappropriate referrals from 324 patients in scenario 1 over the 1-year time horizon.

$\mathrm{TE}$ alone was the most clinically effective strategy in the detection of $\geq \mathrm{F} 3$ fibrosis. Compared to SC, introducing NILT increased the identification of patients with advanced fibrosis (true positive rate) by $30,31,34$ and 36 patients in scenarios 2, 3, 4 and 5 respectively equating to an 114, 118, 129 and $137 \%$ improvement..

Considering cirrhosis specifically, over the 1-year timeframe, employing each of the strategies improved detection by 1 patient per 1000 population compared to the SC,. Specifically, an extra 1.2 (113\%), 1.2 (116\%), 1.3 $(128 \%)$ and $1.4(136 \%)$ cirrhotic patients per 1000

Table 3 Health care costs for patients with NAFLD/ NASH (£, 2014-2015)

\begin{tabular}{|c|c|c|}
\hline Resource Use & Unit Cost & Reference \\
\hline \multicolumn{3}{|l|}{ Primary Care } \\
\hline GP consultation (per patient contact lasting $11.7 \mathrm{~min}$ ) & $£ 45.00$ & [48] \\
\hline \multicolumn{3}{|l|}{ Secondary care } \\
\hline Hepatology Consultant appointment (new) & $£ 148.34$ & Royal Free, February 2015 \\
\hline Hepatology Consultant follow up appt & $£ 98.63$ & Royal Free, February 2015 \\
\hline Dietician review & $£ 57.00$ & Royal Free, February 2015 \\
\hline \multicolumn{3}{|l|}{ Investigations } \\
\hline Routine blood tests (inc. FBC, LFT's, INR) & $£ 68.06$ & Royal Free, February 2015 \\
\hline Liver aetiology panel & $£ 147.98$ & Royal Free, February 2015 \\
\hline FIB-4 (AST/ALT/ platelets included in 'routine blood tests') & $£ 0.00$ & Royal Free, February 2015 \\
\hline ELF & $£ 42.00$ & North Middlesex Hospital, February 2015, \\
\hline Ultrasound Liver & $£ 63.67$ & Royal Free, February 2015 \\
\hline $\mathrm{CT}$ Abdomen/ Liver & $£ 80.78$ & Royal Free, February 2015 \\
\hline MRI Abdomen/ Liver & $£ 101.00$ & Royal Free, February 2015 \\
\hline Fibroscan & $£ 43.00$ & Royal Free, February 2015 \\
\hline Liver biopsy & $£ 642.75$ & Royal Free, February 2015 \\
\hline Endoscopy & $£ 264.00$ & Royal Free, February 2015 \\
\hline \multicolumn{3}{|l|}{ Surgical procedures } \\
\hline Liver resection & $£ 7000$ & [49] \\
\hline Liver transplant (1st year) & $£ 70,000$ & {$[19,49,50]$, Royal Free, February 2015} \\
\hline
\end{tabular}




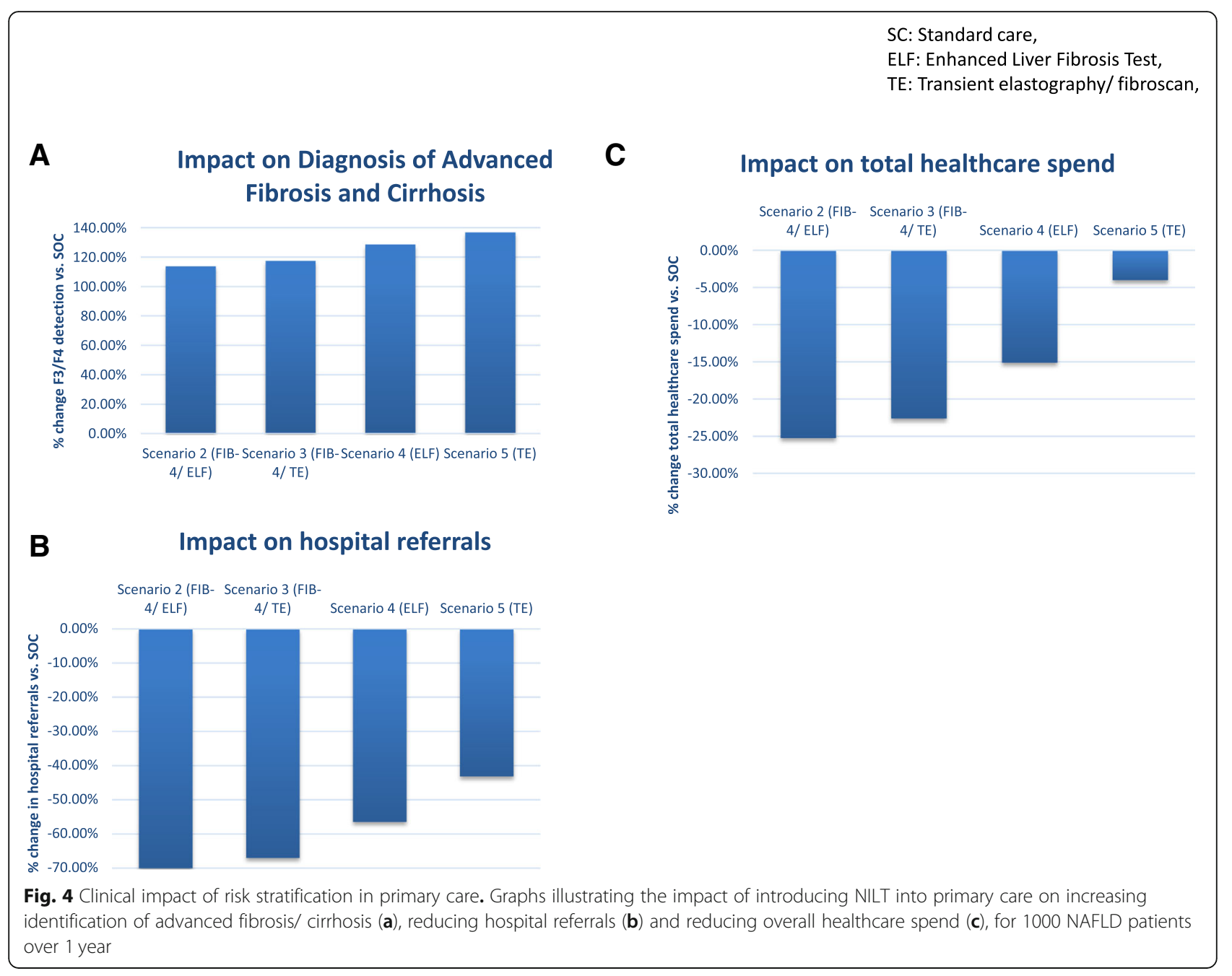

population were detected in scenarios $2,3,4$ and 5 respectively over 1 year compared to SC.

The model tested the impact of earlier detection of advanced fibrosis on complications of CLD (Table 4). Patients known to have cirrhosis routinely undergo regular surveillance. The model demonstrated that the number of patients presenting with curable HCC (Stage O/A) increased from a base case of 0.17 patients per 1000 population following SC, by 0.06 patients per 1000 population in scenarios 2 and 3 and by 0.07 and 0.08 patients per 1000 population in scenarios 4 and 5 respectively. Conversely, over 1 year, incurable HCC (stage B-D), rates decreased from a base case of 0.22 patients per 1000 population following SC the same amounts equivalent to reductions of $29,30,33$ and $35 \%$ for scenarios $2-5$ respectively. Patients presenting with variceal haemorrhage reduced by 0.02 patients per 1000 population in scenarios 2, 3 and 4, and by 0.03 patients per 1000 population in scenario 5 , compared to SOC (0.07 patients per 1000 population). The model predicted that variceal detection through surveillance prior to haemorrhage increased from 0.02 patients per 1000 with SC by 0.02 patients per
1000 in scenarios 2, 3, 4 and 0.03 patients per 1000 in scenario 5 , permitting the instigation of primary prophylaxis of variceal haemorrhage that is associated with reduced mortality [44]. Finally, the model demonstrated that management of cirrhosis in secondary care achieved a reduction in episodes of hospitalization due to other complications of CLD including jaundice, ascites and hepatic encephalopathy from 0.03 patients per 1000 in SC by 0.01 patients per 1000 in all scenarios.

Improvements in the detection and management of cirrhosis would permit increased rates of liver transplantation by 0.02 patients per 1000 in scenarios 2 and 3 and 0.03 patients per 1000 in scenarios 4 and 5, compared to SC $(0.07$ patients per 1000) over 1 year. Predicted all-cause mortality reduced by 0.03 patients per 1000 in scenarios 2 and 3 and 0.04 patients per 1000 in scenarios 4 and 5 over 1 year compared to SC (9.87 patients per 1000).

\section{Cost outcome}

The healthcare costs of the competing strategies are summarised in Fig. 5 using a 1-year horizon. For 1000 
Table 4 Base case analysis of introducing FIB-4, ELF and fibroscan into primary care risk stratification pathways compared to standard of care (scenario 1) after 1 year for 1000 patients with NAFLD

\begin{tabular}{|c|c|c|c|c|}
\hline & $\begin{array}{l}\text { Scenario } 2 \text { - FIB- } \\
\text { 4/ELF }\end{array}$ & $\begin{array}{l}\text { Scenario } 3 \text { - FIB- } \\
4 / \mathrm{TE}\end{array}$ & $\begin{array}{l}\text { Scenario } 4 \text { - } \\
\text { SOC + ELF }\end{array}$ & $\begin{array}{l}\text { Scenario } 5 \text { - } \\
\text { SOC }+ \text { TE }\end{array}$ \\
\hline \multicolumn{5}{|l|}{ Pathway performance: patients referred to specialist (secondary care) } \\
\hline $\begin{array}{l}\text { Incremental number of referrals (stratified as } \geq F 3 \text { fibrosis) } \\
\text { (\% increase vs SOC) }\end{array}$ & $-245(-70 \%)$ & $-222(-67 \%)$ & $-198(-56 \%)$ & $-101(25 \%)$ \\
\hline Incremental number of $\geq \mathrm{F} 3$ disease referred & $30(53 \%)$ & $31(45 \%)$ & $34(39 \%)$ & $36(25 \%)$ \\
\hline Incremental number of $\leq \mathrm{F} 2$ disease referred & $-275(-85 \%)$ & $-253(-78 \%)$ & $-231(-71 \%)$ & $-137(-42 \%)$ \\
\hline Incremental number of cirrhotics referred & $1.16(113 \%)$ & $1.20(116 \%)$ & $1.31(128 \%)$ & $1.40(136 \%)$ \\
\hline \multicolumn{5}{|l|}{ Pathway performance: patients remain under primary care management } \\
\hline $\begin{array}{l}\text { Incremental number of patient stratified as } \leq F 2 \text { fibrosis (Primary } \\
\text { care management) }\end{array}$ & $245(38 \%)$ & $222(34 \%)$ & $198(30 \%)$ & $101(15 \%)$ \\
\hline Incremental number of patients correctly identified as $\leq \mathrm{F} 2$ & $274(46 \%)$ & $253(42 \%)$ & $231(38 \%)$ & $137(23 \%)$ \\
\hline Incremental number of patients incorrectly identified as $\leq F 2$ & $-30(-61 \%)$ & $-31(-63 \%)$ & $-34(-69 \%)$ & $-36(-74 \%)$ \\
\hline \multicolumn{5}{|l|}{ Overall performance of pathways } \\
\hline Sensitivity & 0.75 & 0.76 & 0.80 & 0.83 \\
\hline Specificity & 0.95 & 0.92 & 0.90 & 0.80 \\
\hline Positive Predictive Value & 0.53 & 0.45 & 0.39 & 0.25 \\
\hline Negative Predictive Value & 0.98 & 0.98 & 0.98 & 0.98 \\
\hline Positive Likelihood Ratio & 14.11 & 9.96 & 8.00 & 4.10 \\
\hline Negative Likelihood ratio & 0.27 & 0.26 & 0.22 & 0.21 \\
\hline \multicolumn{5}{|l|}{ Impact on end stage liver disease } \\
\hline $\begin{array}{l}\text { BCLC Stage 0/A curable HCC } \\
\text { (\% of all HCC) }\end{array}$ & $0.06(36 \%)$ & $0.06(38 \%)$ & $0.07(41 \%)$ & $0.08(44 \%)$ \\
\hline BCLC Stage B-D incurable HCC (\% of all HCC) & $-0.06(-29 \%)$ & $-0.07(-30 \%)$ & $-0.07(-33 \%)$ & $-0.08(-35 \%)$ \\
\hline Varices detected via surveillance programme (\% of all new varices) & $0.02(113 \%)$ & $0.02(117 \%)$ & $0.02(128 \%)$ & $0.03(136 \%)$ \\
\hline $\begin{array}{l}\text { Emergency presentation of varices } \\
\text { (\% of all new varices) }\end{array}$ & $-0.02(-30 \%)$ & $-0.02(-31 \%)$ & $-0.02(-34 \%)$ & $-0.03(-36 \%)$ \\
\hline Mild/Moderate 'other' complications & $<0.01(6 \%)$ & $<0.01(6 \%)$ & $<0.01(7 \%)$ & $<0.01(7 \%)$ \\
\hline Severe 'other' complication & $<0.01(-9 \%)$ & $<0.01(-9 \%)$ & $<0.01(-10 \%)$ & $<0.01(-10 \%)$ \\
\hline Number of liver transplants (of all cirrhotics known to specialist) & $0.02(32 \%)$ & $0.02(33 \%)$ & $0.03(36 \%)$ & $0.03(39 \%)$ \\
\hline \multicolumn{5}{|l|}{ Outcomes } \\
\hline Mortality / 1000 NAFLD patients & $-0.03(-0.34 \%)$ & $-0.03(-0.35 \%)$ & $-0.04(-0.39 \%)$ & $-0.04(-0.41 \%)$ \\
\hline
\end{tabular}

Tabulated analysis of the impact of non-invasive liver fibrosis tests for the management of patients with NAFLD (scenarios 2-5) compared to the standard of care (scenario 1) in the primary care setting

patients with NAFLD undergoing PCP assessment for liver disease, the costs directly associated with NILT were $£ 10,385$ in Scenario 2, $£ 10,632$ in scenario 3, $£ 42$, 000 in scenario 4 and $£ 43,000$ in scenario 5 (incorporating additional PCP appointments and blood tests).

Compared to SC (scenario 1) which cost $£ 670,504$ over 1 year, the incremental reductions in healthcare spending achieved through use of NILT in each scenario were $£ 169 \mathrm{~K}, £ 152 \mathrm{~K}, 101 \mathrm{~K}$ and $27 \mathrm{~K}$ per 1000 patients in 1 year in scenarios $2,3,4$ and 5 respectively equating to reductions of 25,23, 15 and 4\%. Using cost-per-case of advanced fibrosis as a surrogate for cost utility, all scenarios were favourable to SC (£25,543.02), with the model predicting cost-per-case of advanced fibrosis at
$£ 8.932 .19, £ 9083.78, £ 9487.26$ and $£ 10,351.67$ in scenarios $2,3,4$ and 5 respectively over the 1 year timeframe.

From a commissioning perspective, a significant contributor to the immediate cost saving was the reduction in secondary care referrals. Compared to scenario 1 ( $£ 41,300$ per 1000 patients over 1 year), cost-savings attributable to reduced specialist referral were $£ 28,895$, $£ 26,216, £ 23,305$ and $£ 11,915$ in scenarios $2,3,4$ and 5 respectively, equating to $70,63,56$ and $29 \%$ reductions.

A budget impact analysis (Table 5) assessed the impact of introducing the interventions nationally in the UK NHS system. Assuming the prevalence of NAFLD to be $20 \%$ in the UK population of 60 million people and a 5year cycle of disease assessment, nationally 2.4 million 


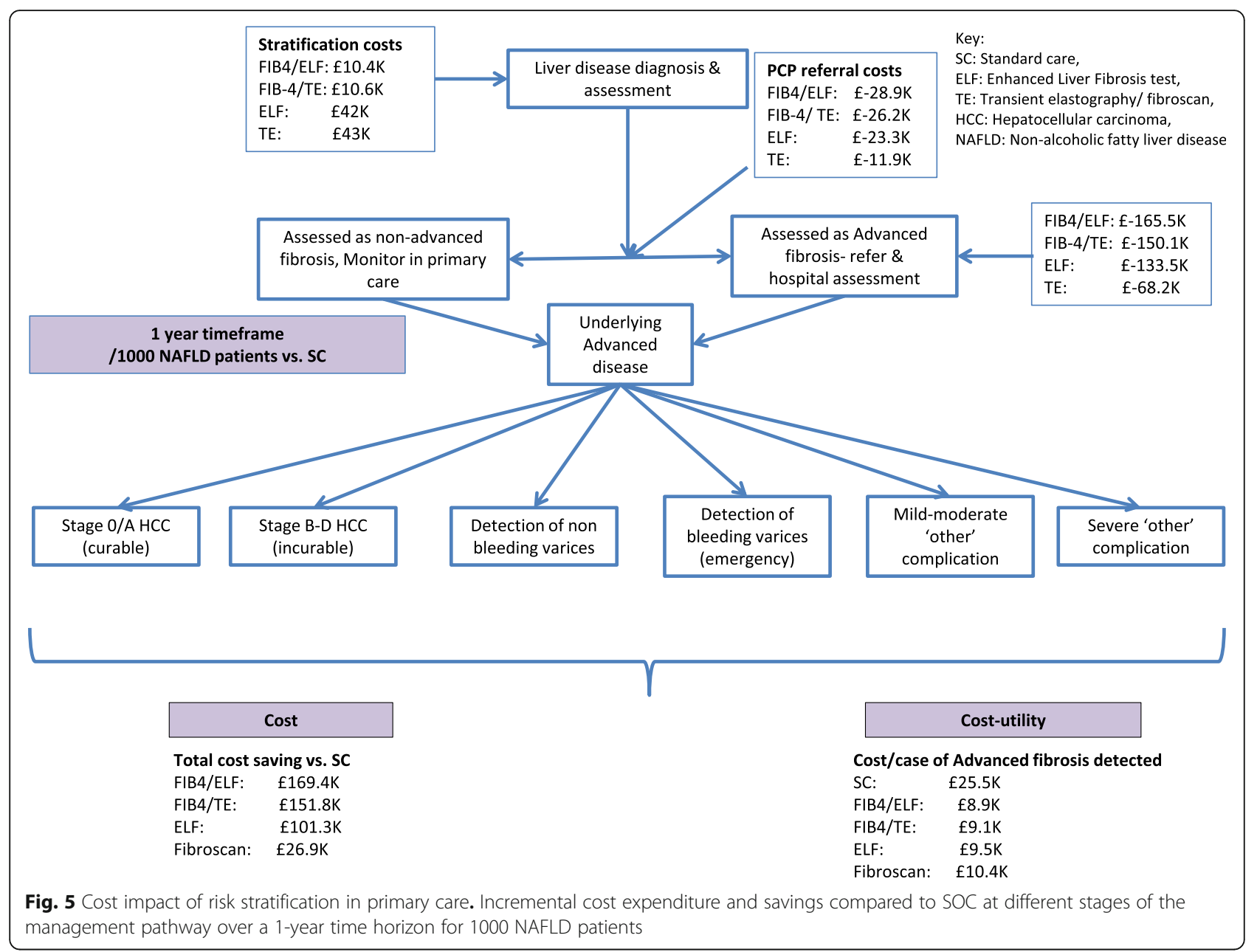

people would potentially be risk stratified annually. The incremental cost to the budget holder of introducing NILT for fibrosis in NAFLD in primary care would be $£ 24.9 \mathrm{M}$, $£ 25.5 \mathrm{M}, £ 100.8 \mathrm{M}$ and $£ 103.2 \mathrm{M}$ in scenario's $2,3,4$ and 5 respectively. However, this would deliver savings equating to $23,21,14$ and $4 \%$ reductions in total healthcare expenditure for each of the scenarios respectively.

Table 6 summarises the outcomes of introducing noninvasive liver fibrosis tests in primary care for the base case.

\section{Projected outcomes over a 5 year timeframe}

Analyses were performed using a five-year horizon to assess the longer-term outcomes of the pathway (Table 7).

Five years after the introduction of NILT the model demonstrated clinical benefit, with increases in the detection of cirrhosis by $107,111,123$ and $132 \%$ in scenarios 2 , 3,4 and 5 respectively equating to an extra $5.69,5.90,6.48$ and 6.95 cases per 1000 patients tested per year.

Using a discount rate of $3.5 \%$, compared to SC over 5 years incremental savings of $£ 168,449.80, £ 142,752.51$,
$£ 86.604 .60$ and $£ 20,769.62$ were made in scenarios 2,3 , 4 , and 5 respectively.

\section{One way sensitivity analyses}

We performed a one-way sensitivity analysis on the base-case scenario using a time-frame of 1 year.

A pathway uptake sensitivity analysis tested assumptions about the proportion of patients entering the pathway $(0-$ $100 \%$ ) and confirmed a linear benefit proportional to pathway uptake and reinforced that any utilisation of the pathway (i.e. $>0 \%$ ) would deliver benefit in all scenarios over the 1-year timeframe.

A clinical effectiveness sensitivity analysis was performed by varying the specificity of SC for the detection of advanced fibrosis. In the base-case model, a value of 0.65 was assumed $(65 \%$ specificity for the detection of advanced fibrosis). To counter the influence of this assumption, around which sparse data are published, it was varied from 0.00 to 1.00 , demonstrating a significant influence on cost-effectiveness. However, the costbenefit was only negated when the specificity of SC for 
Table 5 Budget impact analysis of introducing FIB-4, ELF and fibroscan into primary care risk stratification pathways compared to standard care after 1 year for a population of 60 million patients

\begin{tabular}{|c|c|c|c|c|}
\hline & $\begin{array}{l}\text { Scenario } 2 \text { - FIB-4/ } \\
\text { ELF }\end{array}$ & $\begin{array}{l}\text { Scenario } 3 \text { - FIB-4/ } \\
\text { TE }\end{array}$ & $\begin{array}{l}\text { Scenario } 4-\mathrm{SC}+ \\
\text { ELF }\end{array}$ & $\begin{array}{l}\text { Scenario } 5 \text { - } \\
\text { SC }+ \text { TE }\end{array}$ \\
\hline \multicolumn{5}{|l|}{ Pathway performance: } \\
\hline $\begin{array}{l}\text { Incremental number of referrals (stratified as } \geq \mathrm{F} 3 \text { fibrosis) (\% } \\
\text { increase vs SOC) }\end{array}$ & $-587,700(-70 \%)$ & $-533,217(-67 \%)$ & $-474,000(-56 \%)$ & $-242,340(-25 \%)$ \\
\hline Incremental number of $\geq \mathrm{F} 3$ disease referred & $71,640(53 \%)$ & $74,041(45 \%)$ & $81,000(39 \%)$ & $86,220(25 \%)$ \\
\hline Incremental number of $\leq \mathrm{F} 2$ disease referred & $-659,340(-85 \%)$ & $-607,258(-78 \%)$ & $-555,021(-71 \%)$ & $-328,560(-42 \%)$ \\
\hline Incremental number of cirrhotics referred & $2786(113 \%)$ & $2880(116 \%)$ & $3153(128 \%)$ & $3359(136 \%)$ \\
\hline Incremental number of patients incorrectly identified as $\leq F 2$ & $-71,640(-61 \%)$ & $-74,041(-63 \%)$ & $-81,000(-69 \%)$ & $-86,220(-74 \%)$ \\
\hline \multicolumn{5}{|l|}{ IMPACT ON END STAGE LIVER DISEASE } \\
\hline $\begin{array}{l}\text { BCLC Stage 0/A curable HCC } \\
\text { (\% of all HCC) }\end{array}$ & $121(36 \%)$ & $125(38 \%)$ & $137(41 \%)$ & $146(44 \%)$ \\
\hline BCLC Stage B-D incurable HCC (\% of all HCC) & $-121(-29 \%)$ & $-125(-30 \%)$ & $-137(-33 \%)$ & $-146(-35 \%)$ \\
\hline Varices detected via surveillance programme (\% of all new varices) & $50(113 \%)$ & $51(117 \%)$ & $57(128 \%)$ & $60(136 \%)$ \\
\hline $\begin{array}{l}\text { Emergency presentation of varices } \\
\text { (\% of all new varices) }\end{array}$ & $-50(-30 \%)$ & $-51(-31 \%)$ & $-57(-34 \%)$ & $-60(-36 \%)$ \\
\hline Mild/Moderate 'other' complications & $5(6 \%)$ & $5(6 \%)$ & $6(7 \%)$ & $<6(7 \%)$ \\
\hline Severe 'other' complication requiring hospital admission & $-5(-9 \%)$ & $-5(-9 \%)$ & $-6(-10 \%)$ & $-6(-10 \%)$ \\
\hline \multicolumn{5}{|l|}{ Outcomes } \\
\hline Mortality / 1000 NAFLD patients & $-67(-0.34 \%)$ & $-69(-0.35 \%)$ & $-76(-0.39 \%)$ & $-81(-0.41 \%)$ \\
\hline \multicolumn{5}{|l|}{ Budget } \\
\hline Cost of tests & $£ 24.9 \mathrm{M}$ & $£ 25.5$ & $£ 100.8$ & $£ 103.2 \mathrm{M}$ \\
\hline Total expenditure & $-£ 406 \mathrm{M}(-23 \%)$ & $-£ 364 M(-21 \%)$ & $-£ 243 \mathrm{M}(-14 \%)$ & $-£ 65$ M (-4\%) \\
\hline
\end{tabular}

Tabulated analysis of the impact of non-invasive liver fibrosis tests for the management of patients with NAFLD (scenarios 2-5) compared to the standard of care (scenario 1) in the primary care setting for a population of 60 million patients with $20 \%$ NAFLD prevelance risk stratified on a 5 year cycle

the detection of advanced fibrosis exceeded $0.88,0.86$, 0.80 and 0.68 in scenarios $2,3,4$ and 5 respectively.

\section{Discussion}

Our cost consequence analyses indicate that the use of NILT to stratify patients with NAFLD in primary care is clinically effective and cost saving. Utilizing fibroscan alone was most effective in detecting patients with advanced fibrosis, whilst employing FIB-4 and ELF delivered the greatest cost saving.

All of the scenarios using NILT in primary care permitted the earlier identification of advanced fibrosis/ cirrhosis, creating opportunities to modify fibrosis progression $[22,51]$ and to start surveillance and treatment of varices and HCC. Modelling indicated that significant benefits could accrue from the detection of early stage curable HCC (stage 0/ A) and non-bleeding varices that can be treated with beta-blockers and band ligation that can avert emergency presentations with bleeding varices. A modest reduction in hospital admissions for other complications of CLD including jaundice, ascites and hepatic encephalopathy was demonstrated. The relatively limited impact of current care pathways on mortality, largely attributable to missed or late diagnosis of advanced fibrosis,

Table 6 Summary of outcomes resulting from introducing non-invasive liver fibrosis tests in primary care (per 1000 NAFLD patients over 1 years)

\begin{tabular}{|c|c|c|c|c|c|}
\hline & $\begin{array}{l}\text { Scenario } 1 \\
\text { Standard Care }\end{array}$ & $\begin{array}{l}\text { Scenario } 2 \\
\text { FIB } 4+/- \text { ELF }\end{array}$ & $\begin{array}{l}\text { Scenario } 3 \\
\text { FIB } 4+/- \text { TE }\end{array}$ & $\begin{array}{l}\text { Scenario } 4 \\
\text { ELF }\end{array}$ & $\begin{array}{l}\text { Scenario } 5 \\
\text { TE }\end{array}$ \\
\hline Total Referrals avoided (vs. SOC) & - & 245 & 234 & 198 & 150 \\
\hline Cases F3/F4 detected & 26.3 & 56.1 & 57.1 & 60.0 & 62.2 \\
\hline Cases Cirrhosis detected & 5.3 & 11.0 & 11.2 & 11.8 & 12.3 \\
\hline Cases Cirrhosis missed & 11.3 & 5.5 & 5.3 & 4.7 & 4.2 \\
\hline Cost saving (vs. SOC) & - & $-£ 169,408$ & $-£ 151,816$ & $-£ 101,268$ & - $£ 26,889$ \\
\hline Cost per $\geq$ F3 detected & $£ 25,543$ & $£ 8932$ & $£ 9083$ & $£ 9487$ & $£ 10,351$ \\
\hline
\end{tabular}


Table 7 Projected clinical outcomes and costs of the scenarios projected over 1 year and 5 years

\begin{tabular}{|c|c|c|c|c|c|c|c|c|c|c|}
\hline & \multicolumn{2}{|c|}{ Scenario 1- SC } & \multicolumn{2}{|c|}{$\begin{array}{l}\text { Scenario } 2 \text { - FIB-4/ } \\
\text { ELF }\end{array}$} & \multicolumn{2}{|c|}{$\begin{array}{l}\text { Scenario } 3 \text { - FIB-4/ } \\
\text { TE }\end{array}$} & \multicolumn{2}{|c|}{$\begin{array}{l}\text { Scenario } 4-\mathrm{SC}+ \\
\text { ELF }\end{array}$} & \multicolumn{2}{|c|}{$\begin{array}{l}\text { Scenario } 5-\mathrm{SC}+ \\
\mathrm{TE}\end{array}$} \\
\hline & 1 year & 5 years & 1 year & 5 years & 1 year & 5 years & 1 Year & 5 years & 1 year & 5 years \\
\hline $\begin{array}{l}\text { Total number of cirrhotics entered into } \\
\text { specialist services (out of all cirrhotics) }\end{array}$ & $\begin{array}{l}1.03 \\
(34 \%)\end{array}$ & $\begin{array}{l}5.28 \\
(32 \%)\end{array}$ & $\begin{array}{l}2.19 \\
(74 \%)\end{array}$ & $\begin{array}{l}10.97 \\
(66 \%)\end{array}$ & $\begin{array}{l}2.23 \\
(75 \%)\end{array}$ & $\begin{array}{l}11.17 \\
(68 \%)\end{array}$ & $\begin{array}{l}2.34 \\
(79 \%)\end{array}$ & $\begin{array}{l}11.75 \\
(71 \%)\end{array}$ & $\begin{array}{l}2.43 \\
(82 \%)\end{array}$ & $\begin{array}{l}12.23 \\
(74 \%)\end{array}$ \\
\hline $\begin{array}{l}\text { Total number of cirrhotics not known to } \\
\text { specialist services (out of all cirrhotics) }\end{array}$ & $\begin{array}{l}1.96 \\
(66 \%)\end{array}$ & $\begin{array}{l}11.278 \\
(68 \%)\end{array}$ & $\begin{array}{l}0.78 \\
(26 \%)\end{array}$ & $\begin{array}{l}5.53 \\
(34 \%)\end{array}$ & $\begin{array}{l}0.74 \\
(25 \%)\end{array}$ & $\begin{array}{l}5.41 \\
(32 \%)\end{array}$ & $\begin{array}{l}0.63 \\
(21 \%)\end{array}$ & $\begin{array}{l}4.73 \\
(29 \%)\end{array}$ & $\begin{array}{l}0.54 \\
(18 \%)\end{array}$ & $\begin{array}{l}4.24 \\
(26 \%)\end{array}$ \\
\hline $\begin{array}{l}\text { Early stage complication (stage 0/A HCC, } \\
\text { non-bleeding varices, mild ascites etc) } \\
\text { (\% of all complications) } \\
\text { Cost }\end{array}$ & $\begin{array}{l}0.22 \\
(42 \%) \\
£ 3.0 \mathrm{~K}\end{array}$ & $\begin{array}{l}3.52 \\
(39 \%) \\
£ 31.1 \mathrm{~K}\end{array}$ & $\begin{array}{l}0.31 \\
(57 \%) \\
£ 4.1 \mathrm{~K}\end{array}$ & $\begin{array}{l}4.62 \\
(52 \%) \\
£ 41.2 \mathrm{~K}\end{array}$ & $\begin{array}{l}0.31 \\
(58 \%) \\
£ 4.1 \mathrm{~K}\end{array}$ & $\begin{array}{l}4.66 \\
(52 \%) \\
£ 41.5 K\end{array}$ & $\begin{array}{l}0.32 \\
(60 \%) \\
£ 4.3 \mathrm{~K}\end{array}$ & $\begin{array}{l}4.77 \\
(54 \%) \\
£ 42.6 \mathrm{~K}\end{array}$ & $\begin{array}{l}0.33 \\
(61 \%) \\
£ 4.3 K\end{array}$ & $\begin{array}{l}4.87 \\
(55 \%) \\
£ 43.4 \mathrm{~K}\end{array}$ \\
\hline $\begin{array}{l}\text { Late stage complication (stage B-D HCC, } \\
\text { bleeding varices, severe ascites etc) } \\
\text { (\% of all complications) } \\
\text { Cost }\end{array}$ & $\begin{array}{l}0.32 \\
(58 \%) \\
£ 12.9 \mathrm{~K}\end{array}$ & $\begin{array}{l}5.44 \\
(61 \%) \\
£ 141 \mathrm{~K}\end{array}$ & $\begin{array}{l}0.23 \\
(43 \%) \\
£ 9.2 \mathrm{~K}\end{array}$ & $\begin{array}{l}4.3(48 \%) \\
£ 108 \mathrm{~K}\end{array}$ & $\begin{array}{l}0.23 \\
(42 \%) \\
9.1 \mathrm{~K}\end{array}$ & $\begin{array}{l}4.26 \\
(48 \%) \\
£ 107 K\end{array}$ & $\begin{array}{l}0.22 \\
(40 \%) \\
£ 8.8 \mathrm{~K}\end{array}$ & $\begin{array}{l}4.14 \\
(46 \%) \\
£ 103 K\end{array}$ & $\begin{array}{l}0.21 \\
(39 \%) \\
£ 8.4 \mathrm{~K}\end{array}$ & $\begin{array}{l}4.05 \\
(45 \%) \\
£ 101 \mathrm{~K}\end{array}$ \\
\hline $\begin{array}{l}\text { Liver transplant } \\
\text { Cost }\end{array}$ & $\begin{array}{l}0.07 £ 5.9 \\
K\end{array}$ & $\begin{array}{l}1.05 \\
£ 89.5 \mathrm{~K}\end{array}$ & $\begin{array}{l}0.10 \\
£ 7.9 \mathrm{~K}\end{array}$ & $\begin{array}{l}1.16 \\
£ 98.9 \mathrm{~K}\end{array}$ & $\begin{array}{l}0.10 \\
£ 8.0 \mathrm{~K}\end{array}$ & $\begin{array}{l}1.16 \\
£ 99.3 \mathrm{~K}\end{array}$ & $\begin{array}{l}0.10 \\
£ 8.2 \mathrm{~K}\end{array}$ & $\begin{array}{l}1.17100 .2 \\
K\end{array}$ & $\begin{array}{l}0.10 \\
£ 8.3 \mathrm{~K}\end{array}$ & $\begin{array}{l}1.18 \\
£ 101 \mathrm{~K}\end{array}$ \\
\hline Mortality (\%) & $\begin{array}{l}9.87 \\
0.99 \%\end{array}$ & $\begin{array}{l}28.56 \\
2.86 \%\end{array}$ & $\begin{array}{l}9.84 \\
0.98 \%\end{array}$ & $\begin{array}{l}28.18 \\
2.82 \%\end{array}$ & $\begin{array}{l}9.83 \\
0.98 \%\end{array}$ & $\begin{array}{l}28.17 \\
2.82 \%\end{array}$ & $\begin{array}{l}9.83 \\
0.98 \%\end{array}$ & $\begin{array}{l}28.13 \\
2.81 \%\end{array}$ & $\begin{array}{l}9.83 \\
0.98 \%\end{array}$ & $\begin{array}{l}28.10 \\
2.81 \%\end{array}$ \\
\hline Total cost/1000 NAFLD patients & $638 \mathrm{~K}$ & $1.1 \mathrm{M}$ & $502 \mathrm{~K}$ & $946 \mathrm{~K}$ & $522 \mathrm{~K}$ & $971 \mathrm{~K}$ & $570 \mathrm{~K}$ & $1.0 \mathrm{M}$ & $647 \mathrm{~K}$ & $1.1 \mathrm{M}$ \\
\hline Cost/advanced fibrotic detected & $25.7 \mathrm{~K}$ & $49.9 \mathrm{~K}$ & $9.0 \mathrm{~K}$ & $19.4 \mathrm{~K}$ & $9.1 \mathrm{~K}$ & $19.4 \mathrm{~K}$ & $9.5 \mathrm{~K}$ & $19.5 \mathrm{~K}$ & $10.4 \mathrm{~K}$ & $20.5 \mathrm{~K}$ \\
\hline
\end{tabular}

highlights the need for new approaches to diagnosis and treatment to prevent NAFLD progression.

Of interest to commissioners, the implementation of NILT in primary care offers the potential to reduce the total number of referrals, and in particular the unnecessary referral of patients who have minimal fibrosis. Over a 1 -year horizon, there was a reduction in total referrals of $70,63,56$ and $29 \%$ in scenarios $2,3,4$ and 5 respectively, with an $85,78,71$ and $42 \%$ reduction in referrals of patients with non-advanced disease. Real-world data from a secondary care hepatology service found that $66 \%$ of referred patients had a baseline FIB-4 score $<1.30$ indicating that these patients had a low risk of advanced fibrosis and could have avoided referral [13]. This group of patients represents an inefficient use of resources, adding pressure to overstretched outpatient specialist services and PCP healthcare budgets [52]. Introduction of the use of NILT in primary care would deliver immediate reductions in expenditure through avoidance of unnecessary referrals, unlike the cost-benefits associated with improved outcomes attributable to earlier diagnosis that accrue much later.

All scenarios were cost saving. The cost of detecting a case of advanced fibrosis using SC was $£ 49,917.83$ in scenario. This compared to $£ 19,360.75$ in scenario 2 , $£ 19,448.49$ in scenario $3, £ 19,487.75$ in scenario 4 and $£ 20,451.35$ in scenario 5 . Healthcare budgets were reduced by $17,15,11$ and $3 \%$ in scenarios $2,3,4$ and 5 respectively, attributable to the reduction in costs associated with end stage liver disease and improved resource utilisation. The budget decrease in scenario 5 was modest as it was assumed all patients who failed fibroscan (5\% of cohort) were referred to specialists.
In this analysis, we explored the impact of the use of FIB-4 and ELF to replicate a primary care pathway introduced in north London. This combination of tests was optimal for the stratification of patients in a hospital based population [53] and has subsequently been shown to be clinically effective [13] when applied in primary care where the proportion of cases of advanced fibrosis amongst cases of NAFLD is smaller.

There are limitations to the model. The model was populated with the best available published evidence. A lack of high quality data for some variables was remedied with expert opinion. The measures of performance for FIB-4, ELF and fibroscan were drawn from validations in hospital cohorts, but these estimates may be inappropriately high for primary care populations in which the prevalence of fibrosis is likely to be lower (spectrum bias) $[54,55]$. The model assumes that use of ELF and fibroscan as second-tier tests has the same performance characteristics as a first-tier test. This may under-estimate the performance of the pathway. Additionally, the model was limited to FIB-4, ELF and fibroscan. Local PCP focus groups supported by consultants in Public Health, formed to aide Camden and Islington pathway development, outlined the practical need for simplicity, giving FIB-4 an advantage over the NAFLDfibrosis score, which the PCP considered to be more challenging to obtain such as BMI, or associated with uncertainty about case definition such as diabetes. The model examines fibrosis, but not NASH, and so may underestimate disease progression. Other sources of error include analytical performance. We assumed a 5\% failure rate for fibroscan but higher rates have been reported [47], whilst serum tests can be influenced by comorbidities. For the 
purposes of the model, liver biopsy was considered the reference test for liver fibrosis. Given the inherent inaccuracies associated with liver biopsy [56], this may have overestimated the performance of liver biopsy. The cost estimate of liver biopsy incorporated procedural elements but not those associated with complications of the procedure. This approach may underestimate the true cost associated with liver biopsy. The clinical- and cost- efficiency of all scenarios are highly favourable, but may not reflect real-life outcomes. Not all patients with NAFLD consult their PCP, and pathway uptake by health professionals is variable. The base case is a 50-year-old man with abnormal transaminases, reflecting a screening strategy identified by the Camden and Islington steering committee as practical in reallife primary care practice. However this approach will miss cases of NAFLD with advanced fibrosis but normal LFTs. A screen-all strategy is likely to be clinically optimal, as patients with NAFLD and normal transaminases are at risk of significant fibrosis. The costing in the model is comprehensive, assuming full adherence to guidelines and protocols and thereby potentially overestimating the cost of care. We employed a probabilistic decision model as our main economic focus was on the payer perspective rather than a population health perspective, where alternative costeffectiveness approaches using quality of life data and Markov simulations would be desirable. The lack of beta or triangular distributions and true probability sensitivity analysis limits the model. The model lacks cost/ QALY data and relies on descriptive measures including cost per case of advanced fibrosis detected. These outcome measures have no standard comparator limiting the current model. These shortcomings will be addressed in future work.

NAFLD should be considered as the hepatic manifestation of a multisystem disorder associated with widespread morbidity including cardiovascular disease, diabetes, hyperlipidaemia and cancer. While a fully comprehensive health economic model would need to take these morbidities into consideration we chose to focus on liver disease. Accommodating all NAFLD associated morbidities, their evaluation and management was beyond the scope of this study.

This study has several strengths. A comprehensive literature review was undertaken to identify estimates for clinical parameters, transition rates and costs. The study adds to the current body of evidence and our conclusions are similar to other health economic analyses [57]. A Health Technology Assessment undertaken for the National Institute for Health Research [19] concluded that use of NILT was more cost-effective than liver biopsy in detecting cases of advanced fibrosis. Tapper et al. [58] demonstrated that the use of the NAFLD fibrosis score and fibroscan in primary care yielded cost-effective results. Robust data are lacking regarding the performance of PCP's in the identification of patients with advanced liver disease. Additionally, there is no published randomised controlled trial exploring the performance of NILT in primary care. Whilst limiting the model, the information provided by the analysis may be supplemented with the results from real-life pilot studies in due course. Harman et al. [59] have demonstrated the use of fibroscan in patients with risk factors for CLD, including diabetes, obesity and alcohol excess can increase detection of cirrhosis by $140 \%$, similar to the modelling results in scenario 5 (132\%). Our group has evaluated the pathway employing FIB-4 and ELF (Scenario 2) [13].

\section{Conclusions}

This study demonstrates that the introduction of NILT in primary care has the potential to increase the detection of cases of NAFLD with advanced fibrosis and cirrhosis, reduce unnecessary referrals to secondary care of patients at low risk of liver disease and to deliver immediate and sustained significant cost savings. The model provides compelling evidence for clinicians, commissioners and policy makers to consider the formal introduction of noninvasive liver fibrosis testing in primary care, in line with other central policy statements $[4,60,61]$.

\begin{abstract}
Abbreviations
ALD: Alcoholic liver disease; ALT: Alanine aminotransferase; AST: Aspartate aminotransferase; BCLC: Barcelona Clinic Liver Cancer; CLD: Chronic liver disease; ELF: Enhanced Liver Fibrosis; FIB-4: Fibrosis-4 score; HCC: Hepatocellular carcinoma; HCV: Hepatitis C Virus; LFT: Liver function tests; NAFLD: Non-alcoholic fatty liver disease; NHS: National health system; NILT: Non-invasive liver fibrosis tests; PCP: Primary care physician; SOC: Standard of care
\end{abstract}

\section{Acknowledgements}

Not applicable.

\section{Authors' contributions}

$A S, S J, A G$ and WR were major contributors in study conception and design, acquisition of data, analysis and interpretation of data, drafting of manuscript, and critical revision. RG, SM, KS, ST, JO, ET and JP were involved in acquisition of data and critical revision of the manuscript. EP contributed to analysis and interpretation of data, and critical revision of the manuscript. All authors read and approved the final manuscript.

\section{Funding}

This work was supported by an unrestricted grant from Siemens Healthineers.

The funder had no role in the design of the study, collection, analysis and interpretation of data or writing the manuscript.

\section{Availability of data and materials}

The datasets used and analysed during the current study are available from the corresponding author on reasonable request.

\section{Ethics approval and consent to participate}

This study does not report on animal or human data. It reports theoretical modelling data. Data used for calculating costs in the modelling work were obtained from NHS sources and published literature. Some of the clinical data were drawn from an evaluation of service improvement conducted at The Royal Free London NHS Foundation Trust. The Royal Free London NHS Foundation Trust Research and Development Department judged this work to be an evaluation of a service improvement innovation, therefore this was registered for audit (EDGE ID:122031) but not subject to review by an independent ethics committee and individual patient consent was not 
sought. All activities were performed in accordance with the guidelines of the Helsinki Declaration.

\section{Consent for publication}

Not applicable.

\section{Competing interests}

AS, JP and WR have received speaker bureau from Siemens Healthineers; AS, SJ and WR have received support for research from Siemens Healthineers; WR is a NIHR Senior Investigator and is supported by the UCLH NIHR BRC. EP is supported by the NIHR Collaboration for Leadership in Applied Health Research and Care (CLAHRC) North Thames at Bart's Health NHS Trust. The views expressed are those of the author (s) and not necessarily those of the NHS, the NIHR or the Department of Health and Social Care.

The other authors have no competing interests.

\section{Author details}

${ }^{1}$ UCL Institute for Liver and Digestive Health, Royal Free Campus, London NW3 2PF, UK. ${ }^{2}$ Science Based Business, Leiden University, Snellius Building, Niels Bohrweg 1, 2333 CA Leiden, Netherlands. ${ }^{3}$ Health Economist, 6th Floor, Maple House, 149 Tottenham Court Road, London W1T 7NF, UK.

${ }^{4}$ Department of Primary care and Population Health, Upper 3rd Floor, Royal Free Hospital, London NW3 2PF, UK. ${ }^{5}$ Camden Clinical Commissioning Group, 75 Hampstead Rd, London NW1 2PL, UK. ${ }^{6}$ Islington Clinical Commissioning Group Laycock St, London N1 1TH, UK. 7 Department of Applied Health Research, UCL 1-19 Torrington Place, London WC1E7HB, UK. ${ }^{8}$ Public Health Sciences and Medical Statistics, University of Southampton, Southampton, UK.

Received: 10 October 2018 Accepted: 26 June 2019

Published online: 11 July 2019

\section{References}

1. Scalone L, Fagiuoli S, Ciampichini R, Gardini I, Bruno R, Pasulo L, Lucà MG, Fusco F, Gaeta L, Del Prete A, et al. The societal burden of chronic liver diseases: results from the COME study. BMJ Open Gastroenterol. 2015;0(0):e000025.

2. Neff GW, Duncan CW, Schiff ER. The Current Economic Burden of Cirrhosis. Gastroenterol Hepatol. 2011;7(10):661-71.

3. Office for National Statistics. Mortality statistics: deaths registered in England and Wales (series DR), 2010. In: Newport: Office for National Statistics; 2011.

4. Williams R, Aspinall R, Bellis M, Camps-Walsh G, Cramp M, Dhawan A, Ferguson J, Forton D, Foster G, Gilmore I, et al. Addressing liver disease in the UK: a blueprint for attaining excellence in health care and reducing premature mortality from lifestyle issues of excess consumption of alcohol, obesity, and viral hepatitis. Lancet (London, England). 2014;384(9958):1953-97.

5. Armstrong MJ, Houlihan DD, Bentham L, Shaw JC, Cramb R, Olliff S, Gill PS, Neuberger JM, Lilford RJ, Newsome PN. Presence and severity of nonalcoholic fatty liver disease in a large prospective primary care cohort. J Hepatol. 2012;56(1):234-40.

6. Vernon G, Baranova A, Younossi ZM. Systematic review: the epidemiology and natural history of non-alcoholic fatty liver disease and non-alcoholic steatohepatitis in adults. Aliment Pharmacol Ther. 2011;34(3):274-85.

7. Angulo P, Kleiner DE, Dam-Larsen S, Adams LA, Bjornsson ES, Charatcharoenwitthaya P, Mills PR, Keach JC, Lafferty HD, Stahler A, et al. Liver Fibrosis, but No Other Histologic Features, Is Associated With Long term Outcomes of Patients With Nonalcoholic Fatty Liver Disease. Gastroenterology. 2015;149(2):389-397.e310.

8. Ekstedt M, Hagström H, Nasr P, Fredrikson M, Stål P, Kechagias S, Hultcrantz R. Fibrosis stage is the strongest predictor for disease-specific mortality in NAFLD after up to 33 years of follow-up. Hepatology. 2015;61(5):1547-54.

9. Verma S, Jensen D, Hart J, Mohanty SR. Predictive value of ALT levels for non-alcoholic steatohepatitis (NASH) and advanced fibrosis in non-alcoholic fatty liver disease (NAFLD). Liver Int. 2013;33(9):1398-405.

10. Lam B, Younossi ZM. Treatment options for nonalcoholic fatty liver disease. Ther Adv Gastroenterol. 2010;3(2):121-37.

11. Lay CS, Tsai YT, Teg CY, Shyu WS, Guo WS, Wu KL, Lo KJ. Endoscopic variceal ligation in prophylaxis of first variceal bleeding in cirrhotic patients with high-risk esophageal varices. Hepatology. 1997;25(6):1346-50.

12. Zhang BH, Yang BH, Tang ZY. Randomized controlled trial of screening for hepatocellular carcinoma. J Cancer Res Clin Oncol. 2004;130(7):417-22.
13. Srivastava A, Gailer R, Tanwar S, Trembling P, Parkes J, Rodger A, Suri D, Thorburn D, Sennett K, Morgan S, et al. Prospective evaluation of a primary care referral pathway for patients with non-alcoholic fatty liver disease. J Hepatol. 2019. https://doi.org/10.1016/j.jhep.2019.03.033. [Epub ahead of print]

14. Sebastiani G. Non-invasive assessment of liver fibrosis in chronic liver diseases: Implementation in clinical practice and decisional algorithms. World J Gastroenterol. 2009;15(18):2190-203.

15. National Liver Plan. A time to act: improving liver health and outcomes in liver disease. In: BSG. BSG; 2009.

16. Srivastava A, Gailer R, Tanwar S, Trembling P, Warner A, Morgan S, Sennett K, Thorburn D, Tsochatzis E, Rosenberg W. P1046 : A one year retrospective review of new patient attendances at a tertiary hepatology centre highlighting the increasing challenge of NAFLD and the need to develop clinical pathways. J Hepatol. 2015;62:S740.

17. Ratib S, Fleming KM, Crooks CJ, Aithal GP, West J. 1 and 5 year survival estimates for people with cirrhosis of the liver in England, 1998-2009: A large population study. J Hepatol. 2014;60(2):282-9.

18. McPherson S, Stewart SF, Henderson E, Burt AD, Day CP. Simple noninvasive fibrosis scoring systems can reliably exclude advanced fibrosis in patients with non-alcoholic fatty liver disease. Gut. 2010;59(9):1265-9.

19. Crossan C, Tsochatzis EA, Longworth L, Gurusamy K, Davidson B, RodriguezPeralvarez M, Mantzoukis K, O'Brien J, Thalassinos E, Papastergiou V, et al. Cost-effectiveness of non-invasive methods for assessment and monitoring of liver fibrosis and cirrhosis in patients with chronic liver disease: systematic review and economic evaluation. Health Technol Assess (Winchester, England). 2015;19(9):1-409 v-vi.

20. Guha IN, Parkes J, Roderick P, Chattopadhyay D, Cross R, Harris S, Kaye P, Burt $A D$, Ryder SD, Aithal GP, et al. Noninvasive markers of fibrosis in nonalcoholic fatty liver disease: Validating the European Liver Fibrosis Panel and exploring simple markers. Hepatology (Baltimore, Md). 2008;47(2):455-60.

21. Wong W, Vergniol J, Wong GL, Foucher J, Chan HL, Le Bail B, Choi PC, Kowo M, Chan AW, Merrouche W, et al. Diagnosis of fibrosis and cirrhosis using liver stiffness measurement in nonalcoholic fatty liver disease. Hepatology (Baltimore, Md). 2010;51(2):454-62.

22. Cobbold JFL, Raveendran S, Peake CM, Anstee QM, Yee MS, Thursz MR. Piloting a multidisciplinary clinic for the management of non-alcoholic fatty liver disease: initial 5-year experience. Frontline Gastroenterology. 2013;4(4):263-9.

23. Teli MR, James OF, Burt AD, Bennett MK, Day CP. The natural history of nonalcoholic fatty liver: a follow-up study. Hepatology (Baltimore, Md). 1995;22(6):1714-9.

24. Pais R, Charlotte F, Fedchuk L, Bedossa P, Lebray P, Poynard T, Ratziu V. A systematic review of follow-up biopsies reveals disease progression in patients with non-alcoholic fatty liver. J Hepatol. 2013;59(3):550-6.

25. Ekstedt M, Franzen LE, Mathiesen UL, Thorelius L, Holmqvist M, Bodemar G, Kechagias S. Long-term follow-up of patients with NAFLD and elevated liver enzymes. Hepatology (Baltimore, Md). 2006;44(4):865-73.

26. Adams LA, Lymp JF, St. Sauver J, Sanderson SO, Lindor KD, Feldstein A, Angulo P. The Natural History of Nonalcoholic Fatty Liver Disease: A Population-Based Cohort Study. Gastroenterology. 2005;129(1):113-21.

27. Jepsen P, Vilstrup H, Mellemkjaer L, Thulstrup AM, Olsen JH, Baron JA, Sorensen HT. Prognosis of patients with a diagnosis of fatty liver--a registrybased cohort study. Hepato-gastroenterology. 2003;50(54):2101-4.

28. Pagadala MR, McCullough A. The Relevance of Liver Histology to Predict Clinically Meaningful Outcomes in NASH. Clin Liver Dis. 2012;16(3):487-504.

29. Bhala N, Angulo P, van der Poorten D, Lee E, Hui JM, Saracco G, Adams LA, Charatcharoenwitthaya $P$, Topping $J H$, Bugianesi E, et al. The natural history of nonalcoholic fatty liver disease with advanced fibrosis or cirrhosis: an international collaborative study. Hepatology (Baltimore, Md). 2011;54(4):1208-16.

30. Adams LA, Sanderson S, Lindor KD, Angulo P. The histological course of nonalcoholic fatty liver disease: a longitudinal study of 103 patients with sequential liver biopsies. J Hepatol. 2005;42(1):132-8.

31. Hui JM, Kench JG, Chitturi S, Sud A, Farrell GC, Byth K, Hall P, Khan M, George J. Long-term outcomes of cirrhosis in nonalcoholic steatohepatitis compared with hepatitis C. Hepatology (Baltimore, Md). 2003;38(2):420-7.

32. Sanyal AJ, Banas C, Sargeant C, Luketic VA, Sterling RK, Stravitz RT, Shiffman ML, Heuman D, Coterrell A, Fisher RA, et al. Similarities and differences in outcomes of cirrhosis due to nonalcoholic steatohepatitis and hepatitis C. Hepatology (Baltimore, Md). 2006;43(4):682-9.

33. Fleming KM, Aithal GP, Card TR, West J. The rate of decompensation and clinical progression of disease in people with cirrhosis: a cohort study. Aliment Pharmacol Ther. 2010;32(11-12):1343-50. 
34. Ascha MS, Hanouneh IA, Lopez R, Tamimi TA-R, Feldstein AF, Zein NN. The incidence and risk factors of hepatocellular carcinoma in patients with nonalcoholic steatohepatitis. Hepatology (Baltimore, Md). 2010;51 (6):1972-8.

35. Singal AG, Conjeevaram HS, Volk ML, Fu S, Fontana RJ, Askari F, Su GL, Lok AS, Marrero JA. Effectiveness of Hepatocellular Carcinoma Surveillance in Patients with Cirrhosis. Cancer Epidemiol Biomark Prev. 2012;21(5):793-9.

36. Younossi ZM, Otgonsuren M, Henry L, Venkatesan C, Mishra A, Erario M, Hunt S. Association of nonalcoholic fatty liver disease (NAFLD) with hepatocellular carcinoma (HCC) in the United States from 2004 to 2009. Hepatology. 2015;62(6):1723-30.

37. Estes C, Anstee QM, Arias-Loste MT, Bantel H, Bellentani S, Caballeria J, Colombo M, Craxi A, Crespo J, Day CP, et al. Modeling NAFLD disease burden in China, France, Germany, Italy, Japan, Spain, United Kingdom, and United States for the period 2016-2030. J Hepatol. 2018;69(4):896-904.

38. Matteoni CA, Younossi ZM, Gramlich T, Boparai N, Liu YC, McCullough AJ. Nonalcoholic fatty liver disease: a spectrum of clinical and pathological severity. Gastroenterology. 1999;116(6):1413-9.

39. D'Amico G. Natural History and Stages of Cirrhosis, vol. 1. New York: Springer New York; 2014

40. Reddy SK, Steel JL, Chen H-W, DeMateo DJ, Cardinal J, Behari J, Humar A, Marsh JW, Geller DA, Tsung A. Outcomes of curative treatment for hepatocellular cancer in nonalcoholic steatohepatitis versus hepatitis $C$ and alcoholic liver disease. Hepatology (Baltimore, Md). 2012;55(6):1809-19.

41. Pons F, Varela M, Llovet JM. Staging systems in hepatocellular carcinoma. HPB. 2005;7(1):35-41.

42. Spiegel BM, Esrailian E, Eisen G. The budget impact of endoscopic screening for esophageal varices in cirrhosis. Gastrointest Endosc. 2007;66(4):679-92.

43. Bosch J, Garcia-Pagan JC. Prevention of variceal rebleeding. Lancet (London, England). 2003;361(9361):952-4.

44. Garcia-Tsao G, Sanyal AJ, Grace ND, Carey W. Prevention and management of gastroesophageal varices and variceal hemorrhage in cirrhosis. Hepatology (Baltimore, Md). 2007;46(3):922-38.

45. Singal AG, Pillai A, Tiro J. Early detection, curative treatment, and survival rates for hepatocellular carcinoma surveillance in patients with cirrhosis: a meta-analysis. PLoS Med. 2014;11(4):e1001624.

46. Samonakis DN, Koulentaki M, Coucoutsi C, Augoustaki A, Baritaki C, Digenakis E, Papiamonis N, Fragaki M, Matrella E, Tzardi M, et al. Clinical outcomes of compensated and decompensated cirrhosis: A long term study. World J Hepatol. 2014;6(7):504-12.

47. Castera L, Foucher J, Bernard PH, Carvalho F, Allaix D, Merrouche W, Couzigou P, de Ledinghen V. Pitfalls of liver stiffness measurement: a 5-year prospective study of 13,369 examinations. Hepatology (Baltimore, Md). 2010;51(3):828-35.

48. Curtis LA. Unit Costs of Health \& Social Care 2013. Personal Social Service Research Unit; 2013.

49. Thompson Coon J, Rogers G, Hewson P, Wright D, Anderson R, Cramp M, Jackson S, Ryder S, Price A, Stein K. Surveillance of cirrhosis for hepatocellular carcinoma: systematic review and economic analysis. Health Technol Assess (Winchester, England). 2007;11(34):1-206.

50. Longworth L, Young T, Buxton MJ, Ratcliffe J, Neuberger J, Burroughs A, Bryan S. Midterm cost-effectiveness of the liver transplantation program of England and Wales for three disease groups. Liver Transpl. 2003;9(12):1295-307.

51. Dyson JK, Anstee QM, McPherson S. Non-alcoholic fatty liver disease: a practical approach to treatment. Frontline Gastroenterol. 2014;5(4):277-86.

52. Mehrotra A, Forrest CB, Lin CY. Dropping the Baton: Specialty Referrals in the United States. Milbank Q. 2011;89(1):39-68.

53. Tanwar STP, Hogan B, Thorburn D, Guha I, Parkes I, Kaye P, Burt A, Ryder S, Aithal G, Day C, Rosenberg W. An algorithm combining direct and indirect liver fibrosis tests enhances diagnostic performance for the detection of advanced fibrosis (F3-4) in NAFLD minimising the need for liver biopsy. Hepatology (Baltimore, Md). 2012;56:264A.

54. Schmidt RL, Factor RE. Understanding sources of bias in diagnostic accuracy studies. Arch Pathol Lab Med. 2013;137(4):558-65.

55. Willis BH. Spectrum bias--why clinicians need to be cautious when applying diagnostic test studies. Fam Pract. 2008;25(5):390-6.

56. Ratziu V, Charlotte F, Heurtier A, Gombert S, Giral P, Bruckert E, Grimaldi A, Capron F, Poynard T. Sampling Variability of Liver Biopsy in Nonalcoholic Fatty Liver Disease. Gastroenterology. 2005;128(7):1898-906.
57. Mahady SE, Wong G, Craig JC, George J. Pioglitazone and vitamin E for nonalcoholic steatohepatitis: A cost utility analysis. Hepatology (Baltimore, Md). 2012;56(6):2172-9.

58. Tapper EB, Hunink MG, Afdhal NH, Lai M, Sengupta N. CostEffectiveness Analysis: Risk Stratification of Nonalcoholic Fatty Liver Disease (NAFLD) by the Primary Care Physician Using the NAFLD Fibrosis Score. PLoS One. 2016;11(2):e0147237.

59. Harman DJ, Ryder SD, James MW, Jelpke M, Ottey DS, Wilkes EA, Card TR, Aithal GP, Guha IN. Direct targeting of risk factors significantly increases the detection of liver cirrhosis in primary care: a cross-sectional diagnostic study utilising transient elastography. BMJ Open. 2015;5(4):e007516.

60. Non-alcoholic fatty liver disease (NAFLD): assessment and management; NICE guidelines (NG49). In National Institute for Health and Care Excellence: National Institute for Health and Care Excellence. 2016. http//www.niceorg. uk/guidance/ng49.

61. Newsome PN, Cramb R, Davison SM, Dillon JF, Foulerton M, Godfrey EM, Hall R, Harrower U, Hudson M, Langford A, et al. Guidelines on the management of abnormal liver blood tests. Gut. 2018;67(1):6-19.

\section{Publisher's Note}

Springer Nature remains neutral with regard to jurisdictional claims in published maps and institutional affiliations.
Ready to submit your research? Choose BMC and benefit from:

- fast, convenient online submission

- thorough peer review by experienced researchers in your field

- rapid publication on acceptance

- support for research data, including large and complex data types

- gold Open Access which fosters wider collaboration and increased citations

- maximum visibility for your research: over $100 \mathrm{M}$ website views per year

At BMC, research is always in progress.

Learn more biomedcentral.com/submissions 